\title{
Antiviral bioactivity of resveratrol against Zika virus infection in human retinal pigment epithelial cells
}

\author{
Constanza A. Russo ${ }^{1} \cdot$ María F. Torti $^{1} \cdot$ Agostina B. Marquez $^{1,2} \cdot$ Claudia S. Sepúlveda $^{1,2} \cdot$ Agustina Alaimo $^{1,2}$. \\ Cybele C. García ${ }^{1,2} \mathbb{D}$
}

Received: 22 April 2021 / Accepted: 8 June 2021 / Published online: 20 July 2021

(c) The Author(s), under exclusive licence to Springer Nature B.V. 2021

\begin{abstract}
Resveratrol (RES) is a polyphenol with increasing interest for its inhibitory effects on a wide variety of viruses. Zika virus (ZIKV) is an arbovirus which causes a broad spectrum of ophthalmological manifestations in humans. Currently there is no certified therapy or vaccine to treat it, thus it has become a major global health threat. Retinal pigment epithelium (RPE) is highly permissive and susceptible to ZIKV. This work explored the protective effects of RES on ZIKV-infected human RPE cells. RES treatment resulted in a significant reduction of infectious viral particles in infected male ARPE-19 and female hTERT-RPE1 cells. This protection was positively influenced by the action of RES on mitochondrial dynamics. Also, docking studies predicted that RES has a high affinity for two enzymes of the rate-limiting steps of pyrimidine and purine biosynthesis and viral polymerase. This evidence suggests that RES might be a potential antiviral agent to treat ZIKV-induced ocular abnormalities.
\end{abstract}

Constanza A. Russo and María F. Torti have contributed equally to this work.

Agustina Alaimo and Cybele C. García were senior authors contributed equally to this work.

Cybele C. García

cygarcia@qb.fcen.uba.ar

Agustina Alaimo

aalaimo@qb.fcen.uba.ar

1 Departamento de Química Biológica, Facultad de Ciencias Exactas y Naturales, Universidad de Buenos Aires (UBA), Ciudad Universitaria, Buenos Aires, Argentina

2 Instituto de Química Biológica de la Facultad de Ciencias Exactas y Naturales (IQUIBICEN), Consejo Nacional de Investigaciones Científicas y Técnicas (CONICET), Universidad de Buenos Aires (UBA), Ciudad Universitaria, Buenos Aires, Argentina 


\section{Graphic abstract}

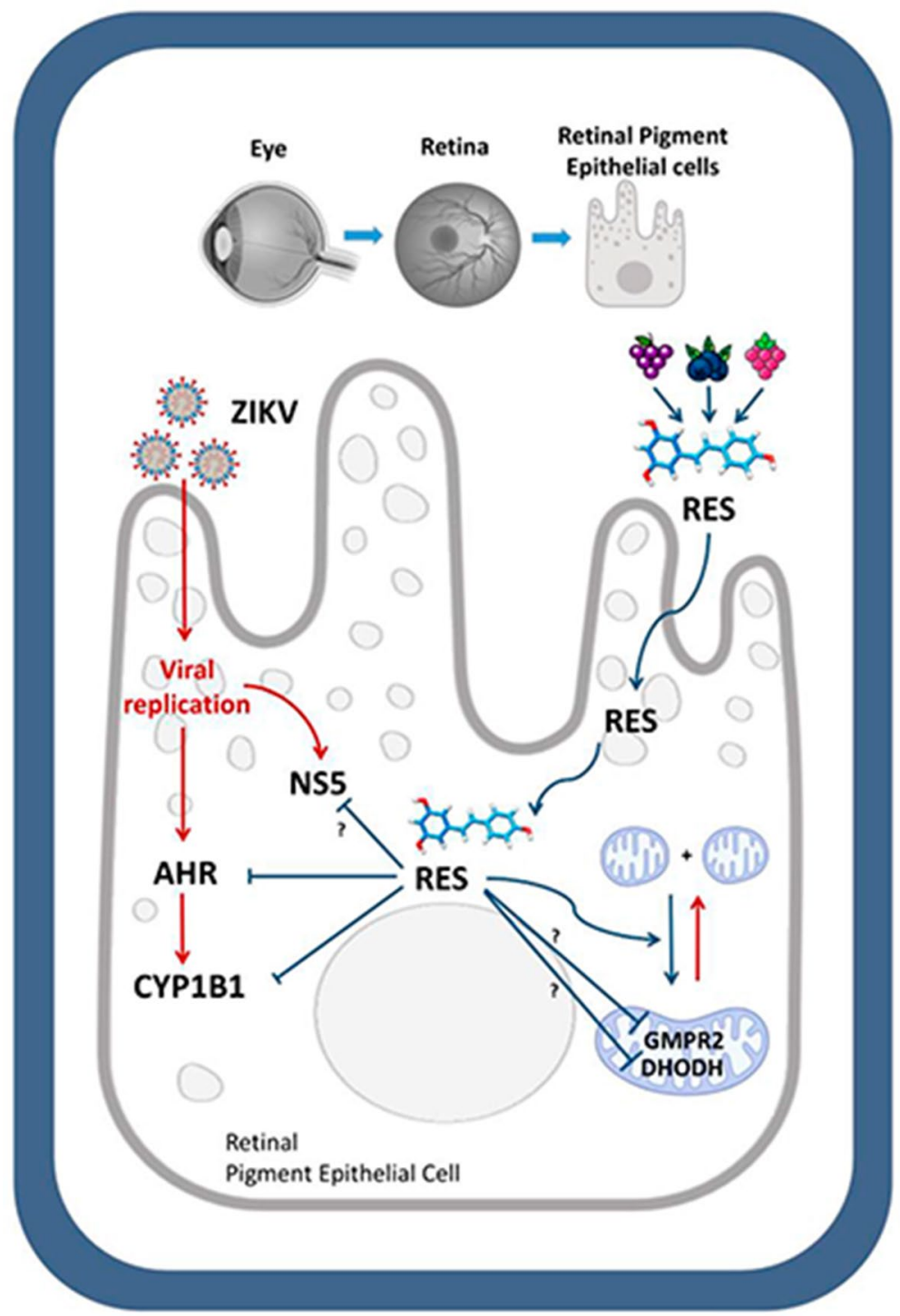

Keywords Polyphenols $\cdot$ Resveratrol $\cdot$ Flavivirus $\cdot$ Zika virus $\cdot$ Retinal pigment epithelium $\cdot$ Antiviral activity

\section{Introduction}

Nature is an inexhaustible source of bioactives. At the present time, there is growing trend of returning to a natural medicine which has been used throughout thousands by different civilizations. As consequence, an increase in the demand to find natural bioactive substances with therapeutic properties with the aim to replace synthetic compounds results mandatory. In line with this, various natural bioactive molecules with beneficial properties for health have been isolated and identified, which forces modern medicine to a paradigm change [1]. Notably, this century has been witnessing of an innovation in natural polyphenolic bioactives due to their myriad of benefits for health (e.g. neurodegenerative disorders) [2].

Polyphenols have been of interest to researchers around the world as potential antiviral agents due to their low toxicity profile and high abundance in nature. So far, more than 10,000 polyphenols have been identified, among which resveratrol (RES) exhibits increasing attention. In recent decades, a wide variety of active phytochemicals exhibited antiviral activities [3]. Resveratrol (RES) is a natural polyphenolic compound that occurs as both trans and cis isomers. RES is mainly found in red wine, skin of red grapes, 
berries, dark chocolate peanuts, and seeds. Polyphenols were postulated to have antiviral properties [4]. In this sense, RES exerted inhibitory effects against influenza A, herpes simplex type 1, rotavirus, Middle East respiratory syndrome, severe acute respiratory syndrome coronavirus-2, dengue (DENV) and Zika (ZIKV) viruses [5-10].

$\mathrm{ZIKV}$ is an arbovirus that consists of an envelope, positive-sense, single-stranded RNA. As well as DENV, yellow fever, West Nile, Japanese encephalitis, and tick-borne encephalitis viruses, ZIKV is member of the Flaviviridae family and is transmitted to humans primarily by infected Aedes mosquitoes. Also human to human infection can occur via blood transfusion, sexual contact and vertically during pregnancy, causing severe neurological damage to the foetus [11]. In 2016, the World Health Organization declared ZIKV epidemic as a public health emergency. Nevertheless, currently there is no treatment or vaccine available [11]. ZIKV occular infection could occur in both, infants and adults as congenital or acquired diseases, respectively. Ophthalmological manifestations includes conjunctivitis, optic nerve hypoplasia, retinal pigmentation changes, haemorrhagic retinopathy, and abnormal retinal vasculature, among others [12].

The RPE is a specialized cell monolayer situated in the interface between the neuroretina and the choriocapillaris where it forms the outer blood-retinal barrier. The RPE plays various physiological roles that are critical to retinal homeostasis, such as: nutrients and ions transport, light absorption, recycling compounds associated with the visual cycle, phagocytosis of photoreceptor outer segments, immune modulation and trophic factors secretion, among others. Hence, the RPE is vital for photoreceptor survival and visual function [13]. The occurrence of viruses or bacteria in RPE cells has been detected in animals, including humans. Additionally, pathogen replication and toxin production can trigger RPE cell death. Accumulating evidence suggest that pathogen-induced chronic infection could be a risk factor in the aetiology of retinal diseases, like age-related macular degeneration [14]. Importantly, it has been indicated that RES treatment might exert positive effects in several ocular pathologies [15].

Although there is knowledge about the clinical manifestations at the ocular level, the amount of scientific background related to the intracellular steps of ZIKV in retinal cells, as well as potential new treatments with natural compounds, remains poorly explored. Therefore, the aim of the current study was to evaluate the potential anti-ZIKV bioactivity of RES in human RPE cells from female and male origin by paying particular attention to the mitochondrial morphology status.

\section{Materials and methods}

\section{Biological and chemical reagents}

\section{Cell lines}

ARPE-19 (ATCC ${ }^{\circledR}$, CRL-2302TM) (karyotype XY) and the human-Telomerase Reverse Transcriptase immortalized RPE cell line (hRPE-1, ATCC ${ }^{\circledR}$ CRL-4000TM) (karyotype XX) were cultured in DMEM (GIBCO) supplemented with $2 \mathrm{mM}$ L-glutamine, $100 \mathrm{IU} / \mathrm{ml}$ penicillin, $100 \mu \mathrm{g} / \mathrm{ml}$ streptomycin, $2.5 \mu \mathrm{g} / \mathrm{ml}$ amphotericin and $10 \%$ fetal bovine serum (FBS) (Sigma-Aldrich).

African green monkey kidney epithelial cells (Vero, ATCC $^{\circledR}$, CCL- $81^{\mathrm{TM}}$ ) were cultured in minimal Eagle essential medium (MEM, GIBCO) supplemented with $100 \mu \mathrm{g} / \mathrm{ml}$ gentamicin, $100 \mu \mathrm{g} / \mathrm{ml}$ streptomycin and 5\% FBS.

\section{Virus}

ZIKV Argentine isolated INEVH116141 (ZIKV-AR) (Instituto Nacional de Enfermedades Virales Humanas (INEVH) Pergamino, Argentina). All work was performed under strict level 2 biosafety working conditions. Infection protocols were approved by the Office of Environmental Health and Safety at the IQUIBICEN-UBA-CONICET.

\section{Chemicals}

trans-RES (RES) (3,5,4'-trihidroxi-trans-estilbeno) (purity $>99 \%$ from Zhejiang Chempharm was provided by Temis Lostaló SA [2]. RES stock of $5 \mathrm{mM}$ was prepared by dissolving the drug in a mixture of $40 \% \mathrm{v} / \mathrm{v}$ ethanol (EtOH) and $60 \% \mathrm{v} / \mathrm{v}$ phosphate-buffered saline (PBS). Other chemicals used were of analytical grade.

\section{Cell viability assay}

ARPE-19 or hRPE-1 cell lines were seeded at a density of 15,000 cells per well on 96-well culture plates for $24 \mathrm{~h}$. When cell cultures yield a 70-80\% confluence, treatments were applied for another $48 \mathrm{~h}$. Cell viability was assessed by MTT assay (Sigma-Aldrich) reduction assay as previously described [2]. Absorbance measurements were performed with an ELISA reader (BIO-RAD).

\section{Viral infection}

ARPE-19 or hRPE-1 cells were grown in 24-well plates. After the medium was removed, $100 \mu \mathrm{l}$ of a dilution of the viral stock in PBS were inoculated to infect with a 
multiplicity of infection (MOI) of 0.5 for $1 \mathrm{~h}$ at $37{ }^{\circ} \mathrm{C} / 5 \%$ $\mathrm{CO}_{2}$, moving the plate every $20 \mathrm{~min}$. Afterwards, the inoculum was removed and $500 \mu \mathrm{l}$ of culture medium was placed in the presence or in the absence RES for $48 \mathrm{~h}$.

\section{Immunofluorescence assay (IFA)}

Cells were fixed with $4 \%$ paraformaldehyde, permeabilized with $0.25 \%$ Triton X-100-PBS $10 \mathrm{~min}$, at room temperature (RT) washed with PBS and incubated in $1 \%$ bovine serum albumin -PBS for $30 \mathrm{~min}$ at RT. Cells were incubated with primary anti-bodies rabbit polyclonal anti-TOM-20 at 1:500 (Santa Cruz Biotechnology, Inc.) and mouse monoclonal anti-E at 1:300 (Abcam, ab155882) for $1 \mathrm{~h}$ at $37^{\circ} \mathrm{C}$. After washing, cells were incubated with the mixture of secondary antibodies: anti-rabbit IgG Alexa Fluor 488 and anti-mouse IgG Alexa Fluor 555 at 1:1000, for $1 \mathrm{~h}$ at $37^{\circ} \mathrm{C}$. Then, washed samples were incubated with DAPI during $10 \mathrm{~min}$ for nuclei labelling. Finally, samples were analysed with an Olympus IX71 epifluorescence microscope and with an Olympus FLUOVIEW FV1000 (Olympus Corporation). Image co-location analysis was performed using the ImageJ (NIH) program. One-hundred cells per sample were quantified and categorized as cells displaying tubular or fragmented (rounded and globular) mitochondria agreeing to Alaimo et al., with slights modifications.

\section{Viral yield determination}

Serial ten-fold dilutions were made from ZIKV-infected cell supernatants in PBS. Samples were used to infect Vero cells using $100 \mu \mathrm{l} /$ well of each dilution. Cells were incubated for $1 \mathrm{~h}$ at $37^{\circ} \mathrm{C}$ and shacked every $20 \mathrm{~min}$. Subsequently, the inoculum was removed and washed. Cells were covered with $1 \mathrm{ml}$ of semi-solid medium (MEM 1\% methylcellulose) and incubated at $37^{\circ} \mathrm{C}$ for 3 days. Then, cells were fixed with $10 \%$ formaldehyde for $10 \mathrm{~min}$, washed and stained with $0.1 \%$ crystal violet in $20 \%$ ethanol. Plaques were counted, and viral yield determined [16].

\section{Bioinformatics analysis}

\section{Homology modelling of ligand binding site domain of AHR}

Amino acid FASTA sequence of AHR was downloaded from Protein Database (Protein ID: NP-001612.1). Amino acid residues of the ligand binding site domain of AHR were selected (272-389). The modelling of the 3Dstructure of the domain of AHR was performed by the homology modelling program SWISS-MODEL $[17,18]$. By using ProMod3, models were built based on the target-template alignment.
Template search with BLAST and HHBlits has been assessed against the SWISS-MODEL template library. Coordinates were copied from the template to the model. Insertions and deletions were remodelled by using a fragment library and then, side chains were rebuilt. The geometry of the resultant model was regularized by applying a force field. The best homology model was selected according to Global Model Quality Estimation (GMQE) and Qualitative Model Energy Analysis (QMEAN) statistical parameters. Model quality and validation were performed using PROCHECK [19], Verify3D [20] and ProSA [21]. Further, docking of known ligands, the agonist TCDD (2,3,7,8-tetrachlorodibenzodioxin) and the antagonist $\mathrm{CH}-223191$ [22] was done.

\section{Molecular docking}

3D ligand structures were drawn using Avogadro2 1.93.0 [23]. The ligands were optimized at semi-empirical PM6 calculations using Gaussian09 [24] and the pdb files were generated by Molden [25]. The following protein crystal structures were obtained from RCSB Protein Data Bank (PDB): Zika NS5 polymerase domain (RdRp) (PDB ID: 6LD5), guanosine 5'-monophosphate oxidoreductase 2 (GMPR2) (PDB ID:2C6Q) dihydroorotate dehydrogenase (DHODH) (PDB ID: 6CJF), and CYP1B1 (PDB ID:3PM0). Ligands and water molecules were deleted from the original protein. Ligands were re-docked into the active site of each protein as a method of re-validation. RES was docked into the active site of the proteins. Molecular docking was performed by AutoDock 4.2.6 software. Protein and ligand structures were managed before molecular docking studies using AutoDock Tools 1.5.6 (Scripps Institute, La Jolla, CA, USA). Gasteiger charges were incorporated into the proteins and atoms were assigned to AD4. For each protein, the AutoGrid program was used to create a grid box to cover the active site of the proteins. Docking simulations were performed using the Lamarckian genetic algorithm (LGA). A total of 300 runs along with $5.10^{6}$ energy evaluations and $1.10^{5}$ iterations were carried out. Docked poses were chosen based on scoring functions. Protein-ligand docked complex structure was visualized using UCSF Chimera [26] and the LigPlot + v.2.1 software was used to study 2D protein-Res interactions.

\section{Statistical analysis}

Experiments were carried out in triplicate. Results are expressed as mean \pm SD values. One-way or two-way ANOVA were applied followed by the Newman-Keuls a posteriori test. Results were considered significant at $\mathrm{p}<0.05$ (GraphPad Prism 6.01 software). 


\section{Results}

\section{Effect of RES on ZIKV-infected RPE cell lines}

RPE are highly permissive to ZIKV replication. To explore the antiviral activity of RES against ZIKV in a retinal cell model, we employed ARPE-19, which is a spontaneously arising RPE cell line of male origin that retains normal karyology and hTERT-RPE-1 (from now on, abbreviated hRPE1 ), which is a near-diploid human cell line of female origin. Both cell lines maintain the morphology and functions of in vivo human RPE cells $[2,16]$.

First, we assessed by MTT reduction test the cytotoxicity effect of different concentrations of RES $(5-250 \mu \mathrm{M})$ on ARPE-19 and hRPE-1 cell lines for 48 h. Figure $1 \mathrm{a}$ and $\mathrm{b}$ denote that RES concentrations higher than $100 \mu \mathrm{M}$ significantly reduced cell viability ( $\mathrm{p}<0.01 \mathrm{vs}$ control), while at lower concentrations there were no significant differences in both cell lines. In accordance with the results obtained, we decided to work with $25-50 \mu \mathrm{M}$ of RES.

Then, we explored the antiviral effects of RES on ZIKV replication. ARPE-19 and hRPE-1 cell lines were infected with ZIKV and following viral adsorption, cell cultures were incubated in the presence or absence of 25 or $50 \mu \mathrm{M}$ RES. After $48 \mathrm{~h}$ of infection, cell morphology was analysed. Figure $1 \mathrm{c}$ and $\mathrm{d}$ shows that ZIKV caused an evident cytopathic effect (CPE) such as cell rounding and lysis. Both cell lines used were equally susceptible to the infection along with the fact that presented similar CPE degrees. The addition of $50 \mu \mathrm{M}$ RES attenuated the CPE in ARPE-19 and hRPE-1 cell lines not only similarly, but also these cells exhibited equivalent morphologies to the cell control cultures (Fig. 1c and d).

To evaluate whether the RES-protective effect during ZIKV infection was due to an in vitro inhibition of viral replication, we quantified by standard plaque assay the impact of the RES treatment on the viral particle production obtained in the supernatant of these cell cultures. As it can be observed in Fig. 1e, in ARPE-19 cells the treatment with 25 and $50 \mu \mathrm{M}$ RES reduced $44 \%$ and $72 \%$ of viral titer, respectively ( $\mathrm{p}<0.001)$. Similarly, 25 and $50 \mu \mathrm{M}$ RES decreased the production of infectious viral particles by $29 \%$ and $75 \%$, respectively $(\mathrm{p}<0.001)$ in hRPE- 1 cells (Fig. 1f). Remarkably, viral production was similar in both cell models, without significant differences in the obtained viral yield $\left(6-7 \times 10^{3} \mathrm{UFP} / \mathrm{ml}\right)$; however, $25 \mu \mathrm{M}$ RES was more effective in terms of reducing the viral titer in ARPE19 in comparison to hRPE- 1 , while $50 \mu \mathrm{M}$ RES inhibited the viral titer in an equivalent effective manner in both cell lines. Hence, we decided to carry out next experimental assays with $50 \mu \mathrm{M}$ RES.
Our results suggested that RES presented a protective role for the RPE cells against ZIKV, since inhibited viral replication and cellular damage.

\section{Effect of RES on mitochondrial dynamics in ZIKV-infected RPE cells}

RES effect depends rigorously on its concentration in both in vitro and in vivo models. For instance, at concentrations lower than $50 \mu \mathrm{M}$, RES exerts antioxidant and cell death protection. In counterpart, RES $>50 \mu \mathrm{M}$ promotes unstable redox environment, rise cytotoxicity, as well as mitochondrial potential membrane loss and apoptosis. Mitochondria are greatly dynamic organelles that move continuously along the cytoskeleton and remodel their morphology by the antagonistic processes of fusion and fission in accordance with cellular demands. The mitochondrial dynamics (MD) process is highly regulated and links the fate of the mitochondria and the cell [2]. The sensitivity of MD to subtle physiological alterations in the cellular redox environment makes it an interesting event to study in relation to the mechanism of an antiviral compound [27]. In addition, we recently proved that ZIKV infection alters the balance of MD towards the fission process in RPE cells [16]. Hence, RPE cell cultures were infected with ZIKV, incubated in the presence or absence of $50 \mu \mathrm{M}$ RES and after $48 \mathrm{~h}$ post infection (p.i.) immunofluorescence assay was performed. Regarding mitochondrial morphologies, as can be seen in Fig. 2a and b, in non-infected RPE cells these organelles presented mostly long tubular shape; however, under ZIKV infection conditions, RPE cells shown rounded, swollen, and fragmented mitochondria. Notably, ZIKV-infected REStreated cells exhibited mitochondrial morphologies similar to non-infected cells.

A detailed observation under confocal microscope allowed the quantification of the mitochondrial morphologies in each sample. Selected images of non-infected (data not shown), ZIKV-infected (Fig. 3a) and ZIKV-infected RES-treated (Fig. 3b) were reconstructed in 2D and 3D with Fiji imaging software by applying "3D Volume" in order to analyse mitochondrial morphologies. In non-infected ARPE-19 cell line (Mock) 90\% of mitochondria were tubular and only $10 \%$ of the cells showed mitochondria with a fragmented shape (data not shown). As expected, in the ZIKV-infected cultures these percentages were significant modified. Only $35 \%$ of the cells presented mitochondria showing tubular morphology $(\mathrm{p}<0.001)$. Finally, in ZIKVinfected RES-treated cells, $54 \%$ of the population presented tubular morphologies. The latter values were significantly different in comparison with the infected $(\mathrm{p}<0.05)$ and nontreated conditions $(p<0.01)$ (Fig. $3 c)$. In accordance, noninfected hRPE- 1 cell line showed $86 \%$ of mitochondria with tubular morphology and only 14\% fragmented (Mock), but 
a

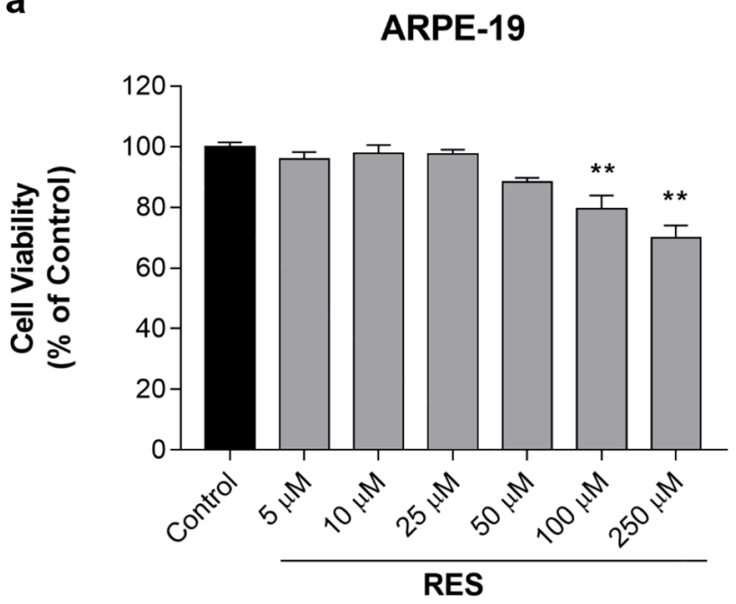

C

\section{ARPE-19}

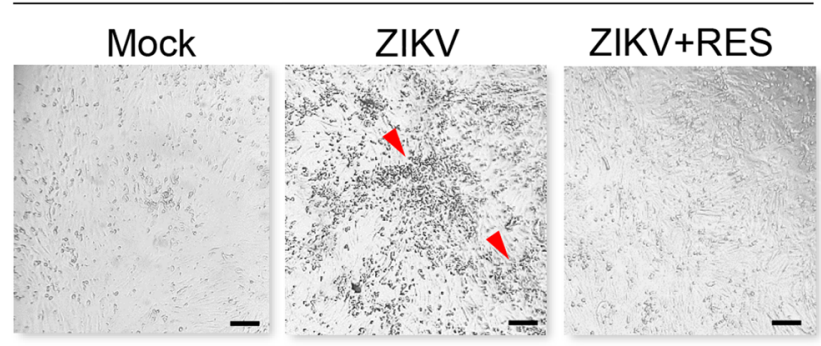

e

ARPE-19

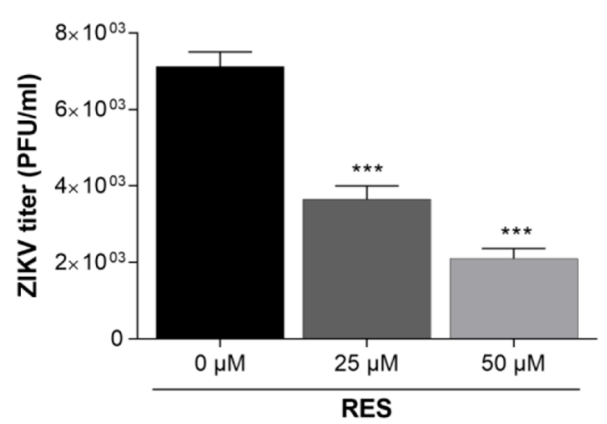

Fig. 1 Effect of RES on ZIKV-infected RPE cells. Determination of the ARPE-19 (a) and hRPE-1 (b) cell viability by the MTT assay. Data were expressed as a percentage of viable cells compared to control (mean \pm SEM). ZIKV and RES effect on cellular morphology in ARPE-19 (c) and hRPE-1 (d). Analysis of cell morphology by phase contrast microscopy of RPE cells mock-infected (first column), ZIKV-infected (second column) or ZIKV-infected and treated with $50 \mu \mathrm{M}$ RES (third column). The photographs were obtained at

in ZIKV-infected samples the percentages changed to 35\% of tubular and $65 \%$ fragmented mitochondria $(\mathrm{p}<0.001)$. Moreover, RES restored the percentage of cells with tubular morphologies to $79 \%(\mathrm{p}<0.01)$ in ZIKV-infected cells. b

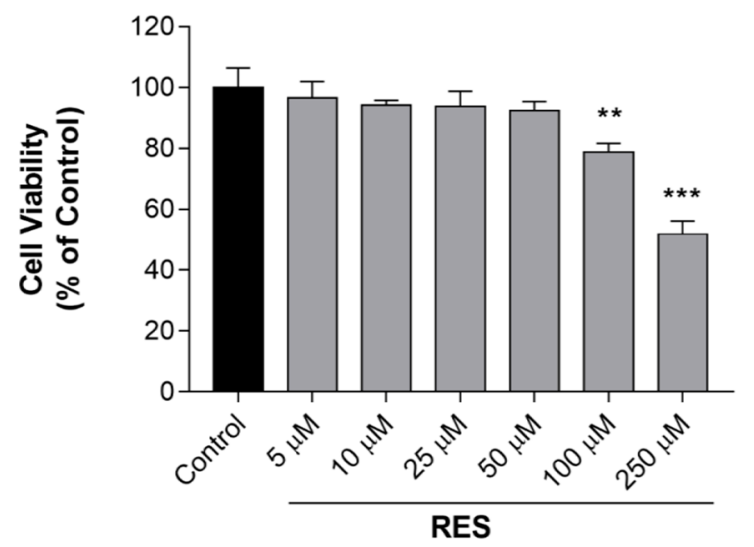

d

\section{hRPE-1}

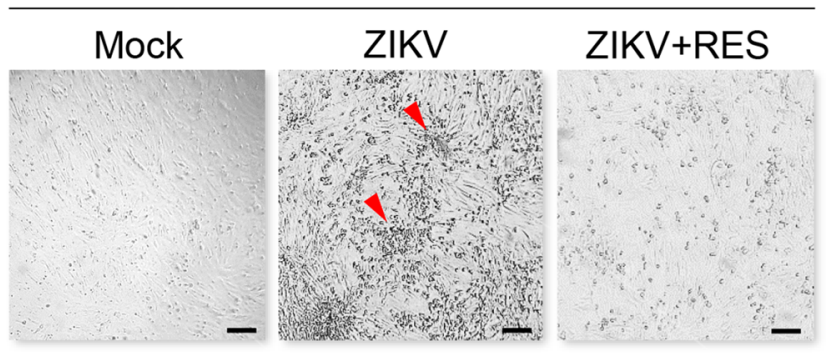

f

hRPE-1

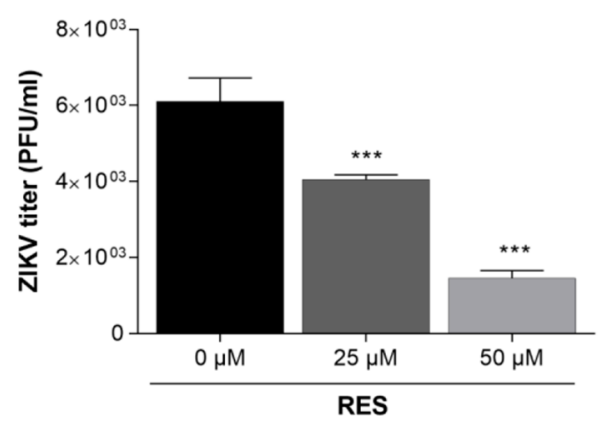

$48 \mathrm{~h}$ p.i (scale bar: $50 \mu \mathrm{m}$ ). Cells presenting cytopathic effect (red arrows). Quantification of the viral yield. Cell cultures of ARPE-19 (e) or hRPE-1 (f) were infected with ZIKV $(\mathrm{moi}=0.5)$ and cultured in the presence or absence of $25 \mu \mathrm{M}$ or $50 \mu \mathrm{M}$ RES. The supernatants of the cultures were harvested at $48 \mathrm{~h} \mathrm{p.i}$ and the viral titer was determined by standard plaque assay (PFU/ml). The statistical analysis by one-way ANOVA with Newman-Keuls post-tests. $* * \mathrm{p}<0.01$; $* * * \mathrm{p}<0.001$ versus control

Notably, in these samples the RES treatment completely restored the rate of tubular mitochondria $(\mathrm{p}<0.05)$ (Fig. 3d).

Collectively, results evidenced that RES prevented the ZIKV-induced mitochondrial morphology disruptions. 


\section{a ARPE-19}

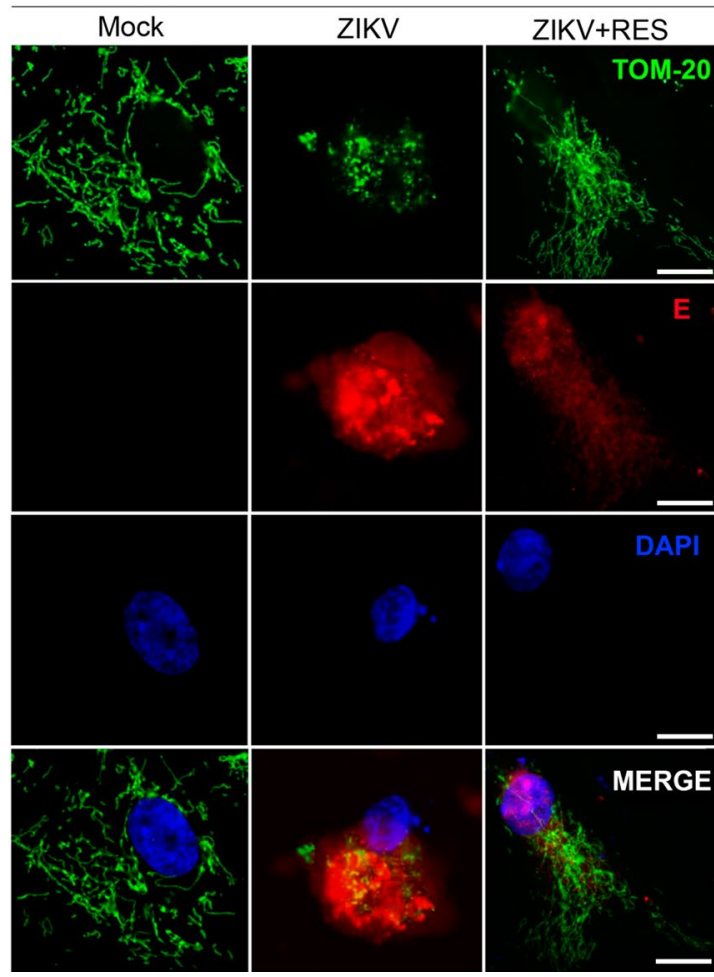

Fig. 2 Effect of RES on mitochondrial morphology of ZIKV-infected RPE cells. Cell cultures of ARPE-19 (a) or hRPE-1 (b) were mockinfected (first column) or infected with ZIKV $(\mathrm{moi}=0.5)$ and cultured in the absence (second column) or presence (third column) of $50 \mu \mathrm{M}$

\section{Mechanism of action of RES against ZIKV infection}

To gain some insights on the antiviral mechanism of action of RES, we applied modelling and docking studies of known and potential RES cellular and viral targets [28]. Particularly, it is well described that RES inhibits the cytochrome P450, family 1 , subfamily B, polypeptide 1 (CYP1B1) expression by preventing the binding of the aryl hydrocarbon receptor (AHR) to promoter sequences that regulate CYP1A1/ CYP1B1 transcription [29]. It was suggested that RES might have a direct action on AHR [30]. Importantly, we recently showed that during ZIKV and DENV infection, AHR transcriptional targets CYP1A1 and CYP1B1 enhanced their expression. Also, we demonstrated that AHR is a druggable pro-viral target for Flaviviruses [11]. Certainly, this activity of RES might represent an important part of the inhibition of ZIKV replication but is not the only mechanism involved. RES also interferes with several phosphorylation signalling pathways, including those activated by protein kinase $\mathrm{C}$ (PKC) and by mitogen-activated protein kinases (MAPKs) [31]. Additionally, RES decreased adenosine triphosphate (ATP) hydrolysis activity of the ZIKV NS3 helicase in vitro [32]. The molecular docking and structural dynamics b

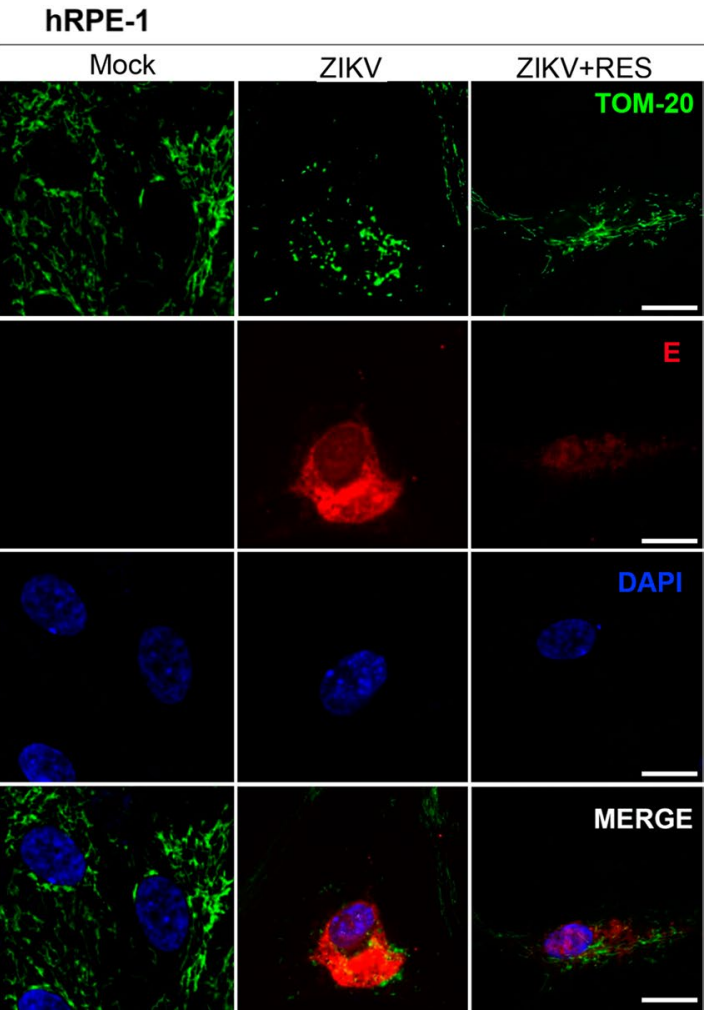

RES. After $48 \mathrm{~h}$, the cells were fixed and then stained against a mitochondrial protein (TOM-20), ZIKV envelope protein (E) and the nuclei (DAPI). The samples were visualized through epifluorescence microscopy. Magnification $60 \times$; scale bar: $10 \mu \mathrm{m}$

simulations revealed that RES stabilizes the P-loop and triggers the RNA-binding loop to block the RNA-binding pocket [33]. Thus diverse mechanisms of action would be operating during the inhibition of ZIKV infection. Also, it has been extensively studied that mitochondrial enzymes of the ratelimiting steps of pyrimidine and purine biosynthesis like the dihydroorotate dehydrogenase (DHODH) and guanosine monophosphate reductase 2 (GMPR2) are essential for the multiplication of RNA viruses [34, 35].

To explore if aforementioned relevant mitochondrial enzymes could also be targeted by RES, we used bioinformatics tools. We included the well-characterized RES target CYP1B1, jointly with AHR, DHODH and GMPR2. Moreover, we analysed the possibility of RES direct action on ZIKV NS5 RNA-dependent RNA polymerase (RdRp). We generated by homology the 3D structure of the ligand binding domain of AHR (PAS-B domain) using SWISSMODEL server. This server was successful in generating the 3D structure using crystal structure of Heterodimeric CLOCK: BMAL1 Transcriptional Activator Complex (PDB ID: 4F3L) as the template. The QMEAN scoring function was -1.60 and the GMQE value was 0.66 . Validation of the model using Ramachandran plot available with 


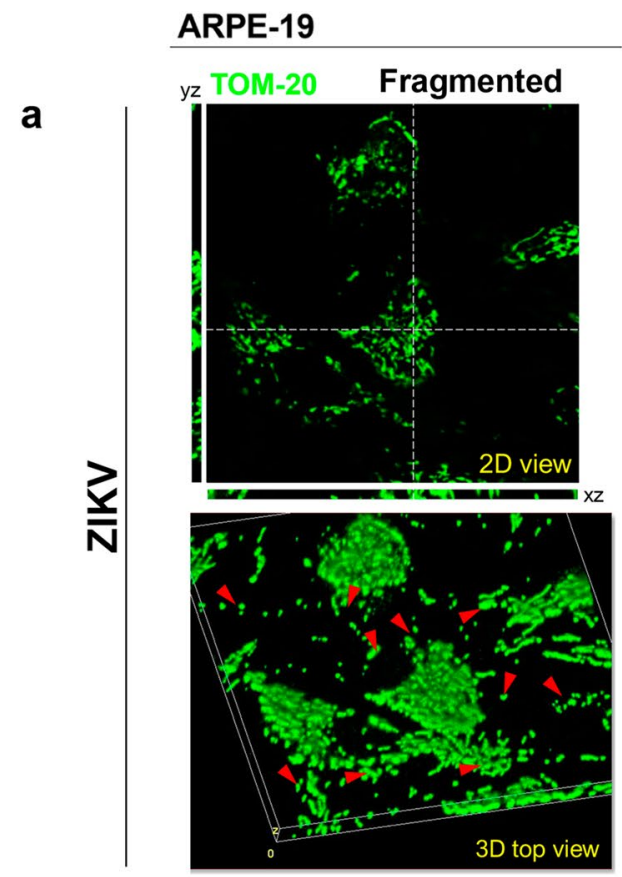

hRPE-1

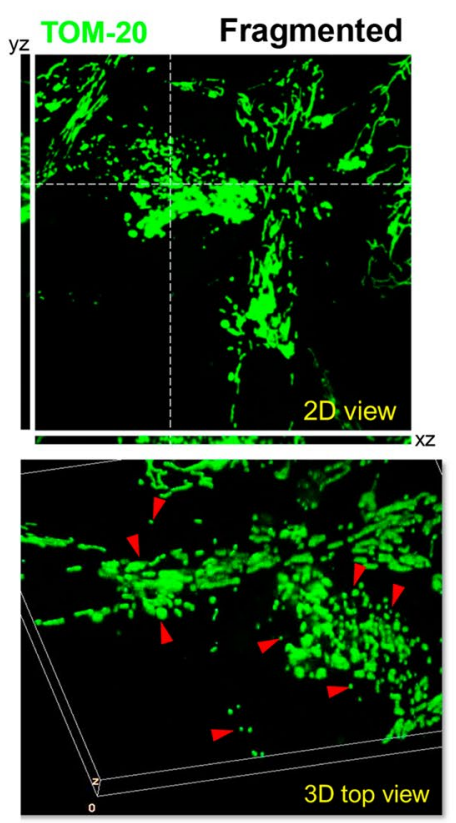

b
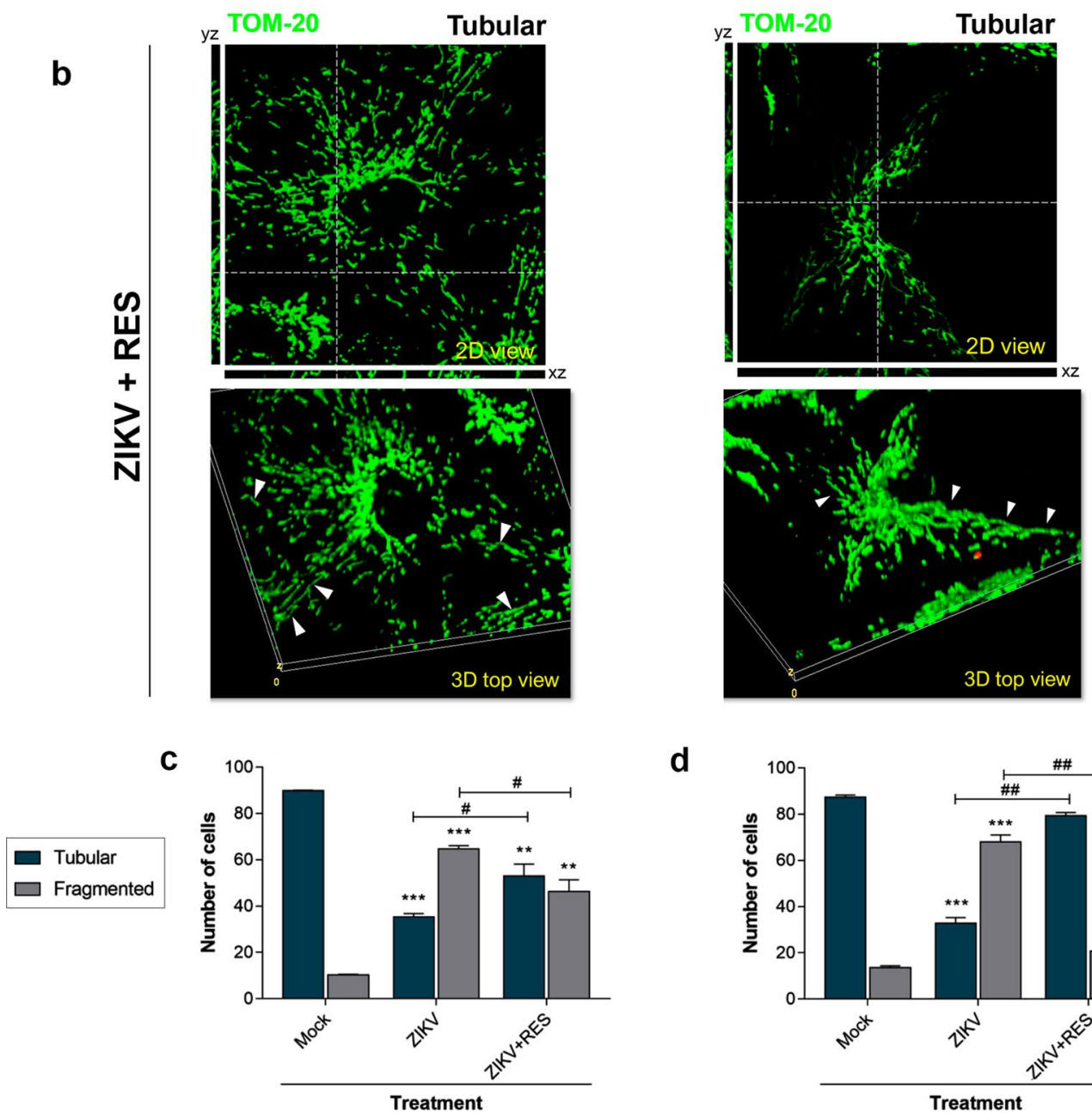

d

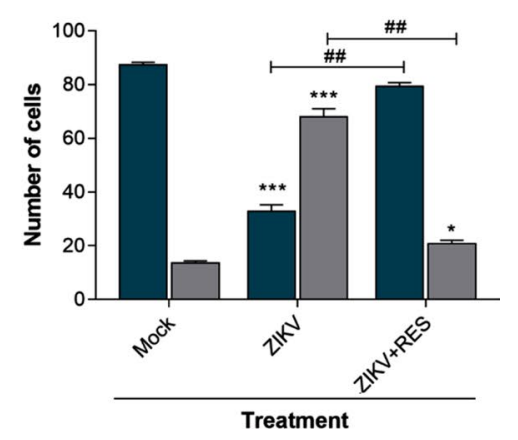


4Fig. 3 Study of the mitochondrial dynamics. Z-stacks representative images from confocal microscopy used for $3 \mathrm{D}$ reconstruction; the crosshairs show the $\mathrm{xz}$ and $\mathrm{yz}$ planes. The images correspond to ZIKV-infected (a) ARPE-19 (left column) and hRPE-1 (right column) cells culture samples or ZIKV-infected and RES-treated (b) ARPE-19 (left column) and hRPE-1 (right column) cells. Different mitochondrial morphologies are indicated. White arrows: m. tubular; red arrows: $\mathrm{m}$. fragmented and swollen. Scale bar: $10 \mu \mathrm{m}$. Quantification of mitochondrial morphologies of ARPE-19 cells (c) or hRPE-1 (d) cells. 100 cells per treatment were counted, and it was determined and plotted the number of cells with distinct mitochondrial morphologies (tubular or fragmented) for each treatment. The statistical analysis was performed through one-way ANOVA *p $<0.05$; \#\# $\mathrm{p}<0.01$; $* * * \mathrm{p}<0.001$ versus control. (Color figure online)

PROCHECK revealed that $91.3 \%$ residues were in the most favored regions, $7.6 \%$ in allowed regions, $1.1 \%$ in generously allowed regions and $0.0 \%$ in the disallowed regions. The parameters plot statistics suggested that the quality of the predicted model was optimal. According to the Verify3D server, the quality factor of the AHR domain residues domain showed that the $94.29 \%$ of the residues had an averaged 3D-1D score $\geq 0.2$ which represents an optimal score. ProSA tool allowed to determine that the $\mathrm{Z}$ score for the model was -4.42 , which is within the range of scores usually found for NMR derived structure for the native protein of comparable size. While the structure assessment reports were relatively good quality for the predicted structure of AHR domain, it was not subjected to loop refinement. The complex AHR domain and the well characterized AHR agonist 2,3,7,8-tetrachlorodibenzodioxin (TCDD) showed a binding energy of $-8.36 \mathrm{kcal} / \mathrm{mol}$ and the complex AHR domain- and the commercial AHR inhibitor CH-223191, an energy of $-9.21 \mathrm{kcal} / \mathrm{mol}$.

The possible mechanisms involved in the activity of RES were carried out through a molecular docking study. The docking process was performed using AutoDock4. Firstly, for the validation of the molecular docking, a re-docking was executed with the co-crystallized ligands and was evaluated that the binding poses coincided. The poses of the co-crystallized ligands overlapped efficiently with the best poses of the docked ligands. Both $2 \mathrm{D}$ and $3 \mathrm{D}$ interactions proteinRES are represented in Fig. 4a, i-iv. CYP1B1 is a known RES target, therefore its binding energy was considered as a reference [36, 37]. Furthermore, known ligands for each protein have been considered as positive controls: TCDD and $\mathrm{CH}-223191$ for AHR, 4,5-dihydroorotic acid (DHO) for DHODH, guanosine monophosphate (GMP) for GMPR2 and ATP for RdRp. The binding energies are represented in Fig. $4 \mathrm{~b}$ and in Table 1 . Affinity values lower than $5 \mathrm{kcal} / \mathrm{mol}$ depicts negligible binding while values closer to $10 \mathrm{kcal} / \mathrm{mol}$ indicates effective binding [38].

The docking study revealed that RES exhibited a strong binding affinity (more than $5 \mathrm{kcal} / \mathrm{mol}$ ) for each protein targets (Table 1 and Fig. 4b). In all cases, the three hydroxyl groups of RES established hydrogen bonds with the protein residues. The most stable complex was RES-DHODH $(-8.15 \mathrm{kcal} / \mathrm{mol})$, even more stable than the complex RESCYP1B1. Nevertheless, the control ligand (DHO) showed more affinity for DHODH $(-8.35 \mathrm{kcal} / \mathrm{mol})$. RES displayed three hydrogen bonds with the amino acid residues of DHODH and ten residues were involved in hydrophobic contacts (Fig. 4a, ii). In the same way, eight of these amino acids coincided with the amino acid that interacted with DHO (Table 2). On the other hand, the GMPR2-RES complex showed a binding affinity of $-7.65 \mathrm{kcal} / \mathrm{mol}$. The complex was less stable than CYP1B1-RES complex but more stable than GMPR2-GMP complex. The higher affinity of RES could be explained by the hydrophobic contacts, while RES interacted with GMPR2 by eleven amino acids, GMP only interacted with eight residues (Table 2). The interactions involved in GMPR2-RES complex were three hydrogen bonds and eleven hydrophobic contacts (Fig. 4a, iii). Residues Cys186 and Gly220 were involved in the GMPR2-GMP complex (Table 2). The AHR-RES complex had a binding energy of $-7.42 \mathrm{kcal} / \mathrm{mol}$, thus the affinity is lower than AHR-TCDD complex $(-8.36 \mathrm{kcal} / \mathrm{mol})$ and AHR-CH-223191 $(-9.21 \mathrm{kcal} / \mathrm{mol})$. The ligand displayed three hydrogen bonds with the residues Tyr39, Gly50 and Gln112, and ten residues of AHR were involved in hydrophobic contacts (Fig. 4a, i). AHR-TCDD complex interacted with eight amino acids as well as the AHR-RES complex (Table 2). Finally, the RdRp-RES complex showed a binding energy of $-7.45 \mathrm{kcal} / \mathrm{mol}$. Although the affinity was lower than CYP1B1-RES, it was higher than ATP-RdRp $(-6.77 \mathrm{kcal} / \mathrm{mol})$. Three RdRp amino acids were involved in hydrogen bond and eight residues were involved in hydrophobic contact (Fig. 4a, iV). In the same way, eleven of these amino acids were involved in the RdRp-ATP complex (Table 2). It is worth noting that RES might interrupt the H-bonds of Tyr768, Thr795, Thr796 and Ser798 residues from RdRp with ATP. In addition, RES has a higher number of hydrophobic contacts, which could explain its higher affinity.

Altogether these results suggested that DHODH, GMPR2 and RdRp are RES potential targets that should be considered as part of it anti-ZIKV action (Fig. 5). 
a

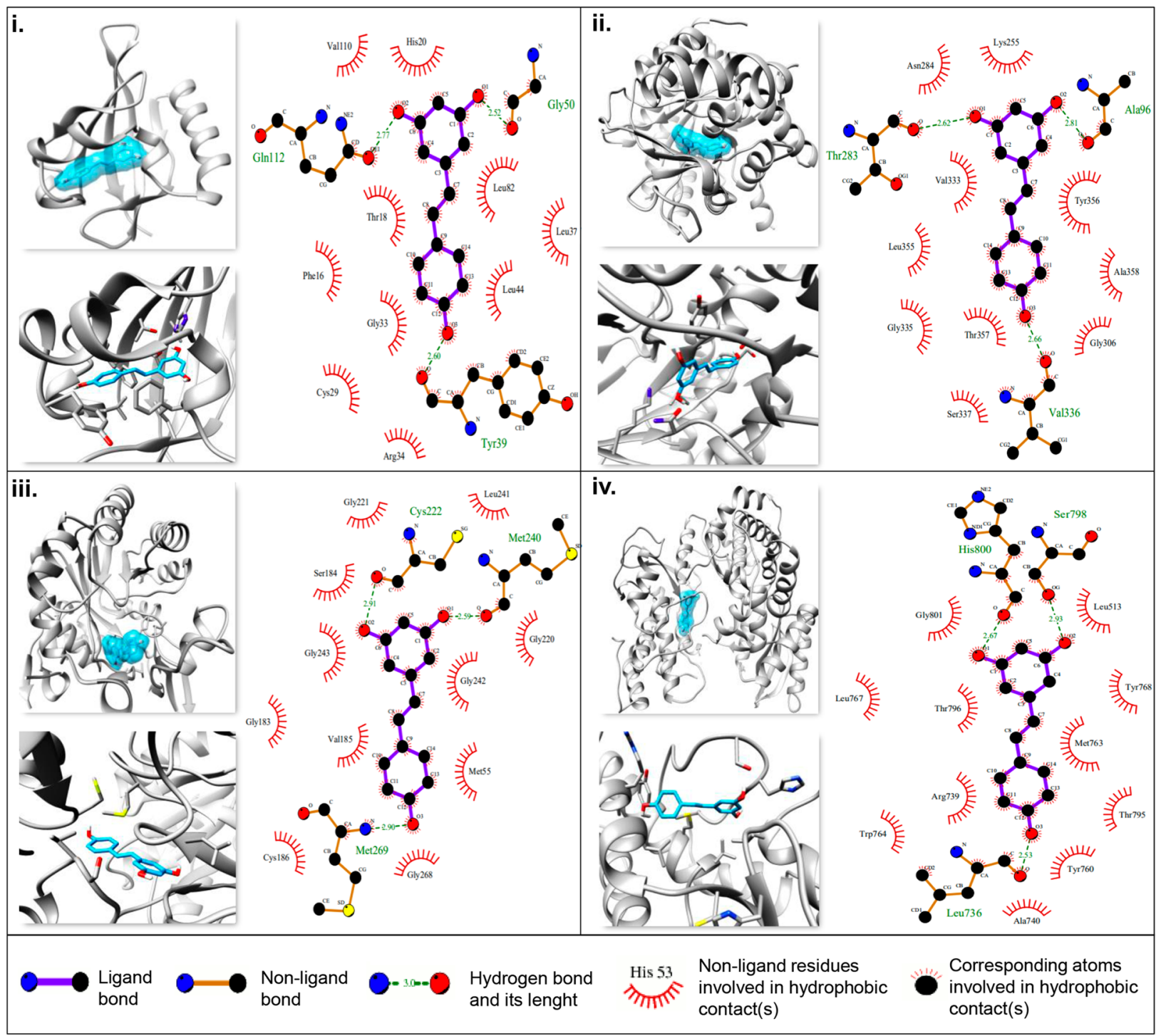

b

Selected analyzed proteins

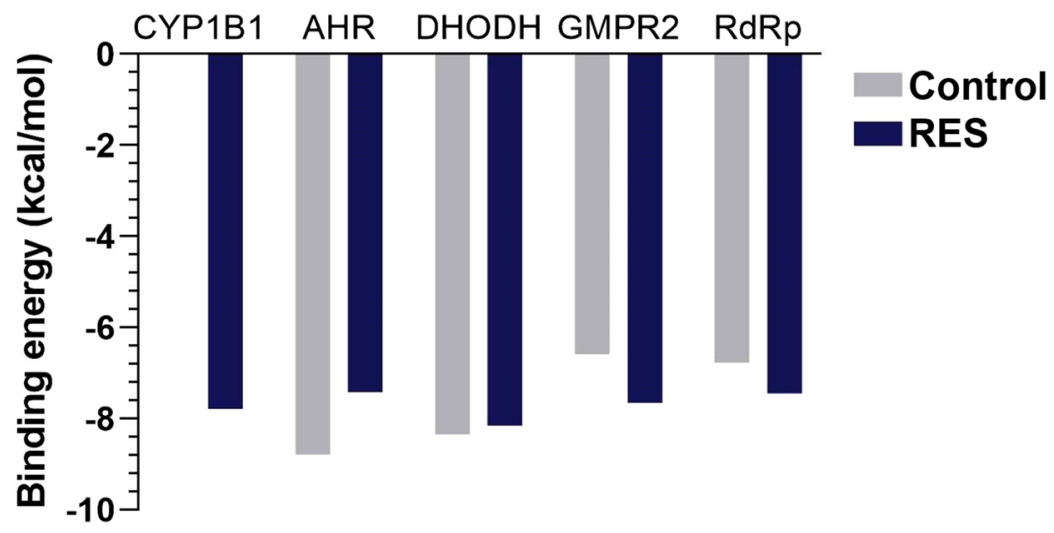


4Fig. 4 Molecular docking of RES with the selected targets. (a) Molecular interactions of RES with (i) AHR (ii) DHODH (iii) GMPR2 (iv) RdRp. The 3D structures of the complexes are visualized with UCSF Chimera and the 2D interactions with $\mathrm{LigPlot}^{+}$v.2.1. In the 3D images, the surface and the structure of RES are represented in cyan color. The proteins are graphed as gray ribbons. (b) Binding energies of the different proteins with RES and the control ligands. Controls: TCDD for AHR, 4,5-dihydroorotic acid (DHO) for DHODH, guanosine monophosphate (GMP) for GMPR2 and adenosine triphosphate (ATP) for RdRp. CYP1B1 is the reference protein. (Color figure online)

\section{Discussion}

Nowadays, several reports indicates that RES may have a great potential in the treatment of several ocular pathologies $[15,39,40]$. Indeed, the antiviral effects of RES related to viral replication inhibition, as well as protein and nuclei acid synthesis and gene expression for different viruses were reported [5-8, 36]. Recently, Mohd et al., determined the ability of RES to inhibit ZIKV replication in the human hepatocellular Huh7 cells. RES exhibited modest virucidal activity against ZIKV but showed antiviral activity in a dose-dependent manner [37]. As far as we know, our report is the first in focusing on the potential antiviral effect of RES during ZIKV infection in human RPE cells.

Table 1 Comparison of binding energies of RES and known ligands with the selected proteins

\begin{tabular}{lll}
\hline Protein & Ligand & $\begin{array}{l}\text { Binding } \\
\text { energy (kcal/ } \\
\text { mol) }\end{array}$ \\
\hline CYP1B1 & Resveratrol & -7.79 \\
AHR & 2,3,7,8-Tetrachlorodibenzodioxin & -8.36 \\
& CH-223191 & -9.21 \\
& Resveratrol & -7.42 \\
DHODH & 4,5-Dihydroorotic acid & -8.35 \\
& Resveratrol & -8.15 \\
GMPR2 & Guanosine monophosphate & -6.59 \\
& Resveratrol & -7.65 \\
RdRp & Adenosine triphosphate & -6.77 \\
& Resveratrol & -7.45 \\
\hline
\end{tabular}

Viruses could modulate MD in order to favour their intracellular survival or elude host immunity. Hence, the interplay between MD and viral pathogenesis represents a novel antiviral strategy [41]. The impact of Flavivirus infection on the MD has been mainly focused on DENV. Those reports showed the existence of a mitochondrial fission and fusion imbalance in infected cells. However, there are controversies about which process is favoured over the other one [42-44]. We demonstrated that ZIKV-infected ARPE-19 and hRPE1 cells exhibited a disbalance of MD toward fission [16]. Notably, there are no other reports that interconnect any type of virus and the positive impact of polyphenols on MD in an ocular context. This report is a pioneer in demonstrating that RES restored the ZIKV-induced fragmented mitochondrial network to almost control conditions. Recently, it was reported that RES positively influenced on disrupted MD in serum deprived-retinal ganglionar R28 cells [45]. Overall, we confirm that RES would be a useful addition in ocular nutritional supplements against ZIKV or related Flavivirus infection, as well as other pathologies in which MD and cell death are associated.

Regarding the mechanism of action of RES, the direct molecular target of this bioactive has been explored. Viruses rely on specific host factors to complete their multiplication cycles. Inhibition of mitochondrial enzymes involved in nucleosides biosynthesis represents a successful antiviral strategy. The inhibition of GMPR2 can deplete guanine nucleotide pools, followed by a decrease in DNA and RNA synthesis. Moreover, the DHODH is a rate-limiting enzyme in the de novo biosynthesis pathway of pyrimidines. Thus, the inhibition of pyrimidines biosynthesis is a potential approach for the treatment of infectious diseases [46]. The predicted inhibition of GMPR2 and DHODH mediated by RES reported here, suggests that these mechanisms may contribute to the blockade of ZIKV replication.

To conclude, we proved that RES inhibited the ZIKVinduced CPE on human RPE and restored the ZIKV-induced MD disruption. Here we suggest a new perspective about the mechanism of action of RES. This involves the interference in the binding of ligand of important cellular enzymes that are essential for viral replication. Our findings indicates that RES might be a potential antiviral agent to treat ZIKVinduced ocular abnormalities. 
Table 2 Amino acids interaction with the natural ligands and RES. Amino acids that interact with RES and the known ligand are shown in bold

\begin{tabular}{|c|c|c|c|}
\hline \multicolumn{2}{|l|}{ Protein } & \multirow{2}{*}{$\begin{array}{l}\begin{array}{l}\text { H-bond } \\
\text { interactions }\end{array} \\
\text { Asn265, Asn228, Gln332 }\end{array}$} & \multirow{2}{*}{$\begin{array}{l}\text { Hydrofobic contact } \\
\text { Phe231, Leu264, Phe268, Gly329, Ala330, Asp333, Thr334, Ile399, } \\
\text { Leu509 and the HEM group }\end{array}$} \\
\hline CYP1B1 & RES & & \\
\hline \multirow[t]{2}{*}{ AHR } & TCDD & - & $\begin{array}{l}\text { Phe16, Thr18, His20, Cys29, Leu37, Tyr39, Leu44, Phe53, His66, } \\
\text { Leu82, Val110, Gln112 }\end{array}$ \\
\hline & RES & Tyr39, Gly50, Gln112 & $\begin{array}{l}\text { Phe16, Thr18, His20, Cys29, Gly33, Arg34, Leu37, Leu44, Leu82, } \\
\text { Val110 }\end{array}$ \\
\hline \multirow[t]{2}{*}{ DHODH } & DHO & $\begin{array}{l}\text { Ala96, Ser120, Asn212, Lys255, Thr283, Asn284, } \\
\text { Gly334, Gly335, Tyr356, Thr357 }\end{array}$ & $\begin{array}{l}\text { Ala95, Gly97, Gly119, Asn145, Thr285, Ser305, Leu309, Val333, } \\
\text { Gln354, Leu355 }\end{array}$ \\
\hline & RES & Ala96, Thr283, Val336 & $\begin{array}{l}\text { Lys255, Asn284, Gly306, Val333, Gly335, Ser337, Leu355, Tyr356, } \\
\text { Thr357, Ala358 }\end{array}$ \\
\hline \multirow[t]{2}{*}{ GMPR2 } & GMP & Ala131, Gly179, Asp219 & Asp129, Asn158, Gly220, Ile180, Gly181, Pro182, Cys186, Thr188 \\
\hline & RES & Cys222, Met240, Met269 & $\begin{array}{l}\text { Met55, Gly183, Ser184, Val185, Cys186, Gly220, Gly221, Leu241, } \\
\text { Gly242, Gly243 Gly268 }\end{array}$ \\
\hline \multirow[t]{2}{*}{$\operatorname{RdRp}$} & ATP & Arg731, Tyr768, Thr795, Thr796, Trp797, Ser798 & Leu513, Leu736, Arg739, Met763, Leu767, His800, Gly801, Trp805 \\
\hline & RES & Leu736, Ser798, His800 & $\begin{array}{l}\text { Leu513, Arg739, Ala740, Tyr760, Met763, Trp764, Leu767, Tyr768, } \\
\text { Thr795, Thr796, Gly801 }\end{array}$ \\
\hline
\end{tabular}
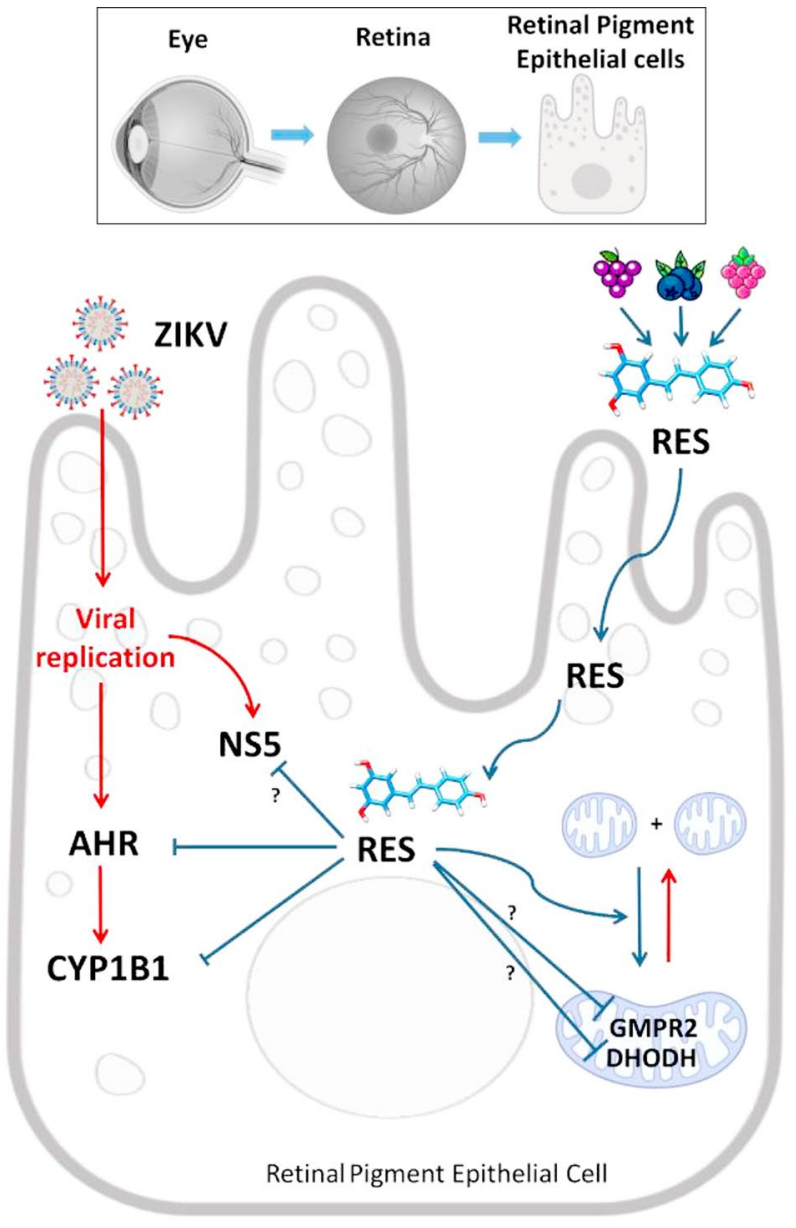

Fig. 5 Proposed scheme describing the potential role of RES against Zika infection in human RPE cells
Acknowledgements We are grateful to all colleagues from our laboratories for helpful advice and discussions.

Author contributions AA and CCG contributed conception and design of the study. CAR, MFT, ABM and CSS performed the experiments and analyzed data. All authors contributed to manuscript revision, read, and approved the submitted version.

Funding This report was supported by Universidad de Buenos Aires (UBA) (20020170100363BA), Consejo Nacional de Investigaciones Científicas y Tecnológicas (CONICET) PIP 11220170100171CO and Agencia Nacional de Promoción Científica y Tecnológica (ANPCyT), Argentina (PICT 2016-1151). CSS, AA, CCG are members of the Research Career from CONICET; ABM is fellow from CONICET and MFT was supported by PhD fellowship from ANPCyT.

\section{Declarations}

Conflict of interest The authors declare that there is no conflict of interest.

Informed consent All authors have given their consent to participate in this report and submit it to Molecular Biology Reports.

\section{References}

1. Tufarelli V, Casalino E, D’Alessandro AG, Laudadio V (2017) Dietary phenolic compounds: biochemistry, metabolism and significance in animal and human health. Curr Drug Metab 18:905913. https://doi.org/10.2174/1389200218666170925124004

2. Alaimo A, Di Santo M, Domínguez Rubio A et al (2020) Toxic effects of A2E in human ARPE-19 cells were prevented by resveratrol: a potential nutritional bioactive for age-related macular degeneration treatment. Arch Toxicol 94:553-572. https://doi.org/ 10.1007/s00204-019-02637-w 
3. Naithani R, Huma L, Holland L et al (2008) Antiviral activity of phytochemicals: a comprehensive review. Mini-Rev Med Chem 8:1106-1133. https://doi.org/10.2174/138955708785909943

4. Koushki M, Amiri-Dashatan N, Ahmadi N et al (2018) Resveratrol: a miraculous natural compound for diseases treatment. Food Sci Nutr 6(8):2473-2490

5. Palamara AT, Nencioni L, Aquilano K et al (2005) Inhibition of influenza a virus replication by resveratrol. J Infect Dis 191:1719_ 1729. https://doi.org/10.1086/429694

6. Annunziata G, Maisto M, Schisano C et al (2018) Resveratrol as a novel anti-herpes simplex virus nutraceutical agent: an overview. Viruses. https://doi.org/10.3390/v10090473

7. Mohd A, Zainal N, Tan KK, AbuBakar S (2019) Resveratrol affects Zika virus replication in vitro. Sci Rep 9:1-11. https://doi. org/10.1038/s41598-019-50674-3

8. Huang H, Liao D, Zhou G et al (2020) Antiviral activities of resveratrol against rotavirus in vitro and in vivo. Phytomedicine. https://doi.org/10.1016/j.phymed.2020.153230

9. Lin SC, Ho CT, Chuo WH et al (2017) Effective inhibition of MERS-CoV infection by resveratrol. BMC Infect Dis 17:144. https://doi.org/10.1186/s12879-017-2253-8

10. Yang M, Wei J, Huang T et al (2020) Resveratrol inhibits the replication of severe acute respiratory syndrome coronavirus 2 ( SARS-CoV -2) in cultured vero cells. Phyther Res 35(3):11271129. https://doi.org/10.1002/ptr.6916

11. Giovannoni F, Bosch I, Polonio CM et al (2020) AHR is a Zika virus host factor and a candidate target for antiviral therapy. Nat Neurosci 23:939-951. https://doi.org/10.1038/s41593-020-0664-0

12. Fernando Martínez-Pulgarín D, Miguel Córdoba-Ortega C, Daniel Padilla-Pantoja F (2019) The eye and the Zika virus. Zika virus disease. IntechOpen, London

13. Strauss $O$ (2005) The retinal pigment epithelium in visual function. Physiol Rev. https://doi.org/10.1152/physrev.00021.2004.Located

14. Qin S, Rodrigues GA (2008) Progress and perspectives on the role of RPE cell inflammatory responses in the development of age-related macular degeneration. J Inflamm Res 1:49. https://doi. org/10.2147/jir.s4354

15. Abu-Amero KK, Kondkar AA, Chalam KV (2016) Resveratrol and ophthalmic diseases. Nutrients 8(4):200. https://doi.org/10. 3390/nu8040200

16. García CC, Vázquez CA, Giovannoni F et al (2020) Cellular Organelles reorganization during Zika virus infection of human cells. Front Microbiol 11:1-13. https://doi.org/10.3389/fmicb.2020. 01558

17. Studer G, Rempfer C, Waterhouse AM et al (2020) QMEANDisCo-distance constraints applied on model quality estimation. Bioinformatics 36:1765-1771. https://doi.org/10.1093/bioinforma tics/btz828

18. Waterhouse A, Bertoni M, Bienert S et al (2018) SWISS-MODEL: Homology modelling of protein structures and complexes. Nucleic Acids Res 46:W296-W303. https://doi.org/10.1093/nar/gky427

19. Laskowski RA, MacArthur MW, Moss DS, Thornton JM (1993) PROCHECK: a program to check the stereochemical quality of protein structures. J Appl Crystallogr 26:283-291. https://doi.org/ $10.1107 / \mathrm{s} 0021889892009944$

20. Eisenberg D, Lüthy R, Bowie JU (1997) VERIFY3D: assessment of protein models with three-dimensional profiles. Methods Enzymol 277:396-404. https://doi.org/10.1016/S0076-6879(97) $77022-8$

21. Wiederstein M, Sippl MJ (2007) ProSA-web: interactive web service for the recognition of errors in three-dimensional structures of proteins. Nucleic Acids Res. https://doi.org/10.1093/nar/ gkm290

22. Ghosh J, Chowdhury AR, Srinivasan S et al (2018) Cigarette smoke toxins-induced mitochondrial dysfunction and pancreatitis involves aryl hydrocarbon receptor mediated Cyp1 gene expression: protective effects of resveratrol. Toxicol Sci 166:428-440. https://doi.org/10.1093/toxsci/kfy206

23. Hanwell MD, Curtis DE, Lonie DC et al (2012) Avogadro: an advanced semantic chemical editor, visualization, and analysis platform. J Cheminform. https://doi.org/10.1186/1758-2946-4-17

24. Frisch MJ, GW T, HB S, et al (2009) G09 I Gaussian.com. https:// gaussian.com/glossary/g09/. Accessed 17 Dec 2020

25. Schaftenaar G, Vlieg E, Vriend G (2017) Molden 2.0: quantum chemistry meets proteins. J Comput Aided Mol Des 31:789-800. https://doi.org/10.1007/s10822-017-0042-5

26. Pettersen EF, Goddard TD, Huang CC et al (2004) UCSF chimera - a visualization system for exploratory research and analysis. J Comput Chem 25:1605-1612. https://doi.org/10.1002/jcc. 20084

27. Khan M, Syed GH, Kim SJ, Siddiqui A (2015) Mitochondrial dynamics and viral infections: a close nexus. Biochim Biophys Acta - Mol Cell Res 1853:2822-2833

28. Tennen RI, Michishita-Kioi E, Chua KF (2012) Finding a target for resveratrol. Cell 148:387-389

29. Pastorková B, Vrzalová A, Bachleda P, Dvořák Z (2017) Hydroxystilbenes and methoxystilbenes activate human aryl hydrocarbon receptor and induce CYP1A genes in human hepatoma cells and human hepatocytes. Food Chem Toxicol 103:122-132. https://doi. org/10.1016/j.fct.2017.03.008

30. De Medina P, Casper R, Savouret JF, Poirot M (2005) Synthesis and biological properties of new stilbene derivatives of resveratrol as new selective aryl hydrocarbon modulators. J Med Chem 48:287-291. https://doi.org/10.1021/jm0498194

31. Pirola L, Fröjdö S (2008) Resveratrol: one molecule many targets. IUBMB Life 60(5):323-332. https://doi.org/10.1002/iub.47

32. Saw WG, Pan A, Subramanian Manimekalai MS, Grüber G (2017) Structural features of Zika virus non-structural proteins 3 and -5 and its individual domains in solution as well as insights into NS3 inhibition. Antiviral Res 141:73-90. https://doi.org/10.1016/j. antiviral.2017.02.005

33. Devnarain N, Soliman MES (2019) Molecular mechanism of resveratrol inhibition of Zika virus NS3 helicase: behind the scenes. Future Virol 14:73-84

34. Sepulveda CS, Fascio ML, Garcia CC et al (2013) Acridones as antiviral agents: synthesis, chemical and biological properties. Curr Med Chem 20:2402-2414. https://doi.org/10.2174/09298 67311320190002

35. Sepúlveda CS, García CC, Fascio ML et al (2012) Inhibition of Junin virus RNA synthesis by an antiviral acridone derivative. Antiviral Res 93:16-22. https://doi.org/10.1016/j.antiviral.2011. 10.007

36. Yang T, Li S, Zhang X et al (2015) Resveratrol, sirtuins, and viruses. Rev Med Virol 25:431-445. https://doi.org/10.1002/rmv. 1858

37. Han YS, Penthala NR, Oliveira M et al (2017) Identification of resveratrol analogs as potent anti-dengue agents using a cell-based assay. J Med Virol 89:397-407. https://doi.org/10.1002/jmv.24660

38. Mishra A, Dey S (2019) Molecular docking studies of a cyclic octapeptide-cyclosaplin from sandalwood. Biomolecules 9(11):740. https://doi.org/10.20944/preprints201906.0091.v1

39. Alaimo A, Di Santo M, Dominguez Rubio A et al (2020) Toxic effects of A2E in human ARPE-19 cells were prevented by resveratrol : a potential nutritional bioactive for age-related macular degeneration treatment. Arch Toxicol 94:553-562. https://doi.org/ 10.1007/s00204-019-02637-w

40. Nashine S, Nesburn AB, Kuppermann BD, Kenney MC (2020) Role of resveratrol in transmitochondrial AMD RPE cells. Nutrients. https://doi.org/10.3390/nu12010159 
41. Ren Z, Zhang X, Ding T et al (2020) Mitochondrial dynamics imbalance: a strategy for promoting viral infection. Front Microbiol. https://doi.org/10.3389/fmicb.2020.01992

42. Yu CY, Liang JJ, Li JK et al (2015) Dengue virus impairs mitochondrial fusion by cleaving mitofusins. PLoS Pathog. https://doi. org/10.1371/journal.ppat.1005350

43. Barbier V, Lang D, Valois S et al (2017) Dengue virus induces mitochondrial elongation through impairment of Drp1-triggered mitochondrial fission. Virology 500:149-160. https://doi.org/10. 1016/j.virol.2016.10.022

44. Chatel-Chaix L, Cortese M, Romero-Brey I et al (2016) Dengue virus perturbs mitochondrial morphodynamics to dampen innate immune responses. Cell Host Microbe 20:342-356. https://doi. org/10.1016/j.chom.2016.07.008

45. Pang Y, Qin M, Hu P et al (2020) Resveratrol protects retinal ganglion cells against ischemia induced damage by increasing Opa1 expression. Int J Mol Med 46:1707-1720. https://doi.org/ 10.3892/ijmm.2020.4711

46. Munier-Lehmann H, Vidalain PO, Tangy F, Janin YL (2013) On dihydroorotate dehydrogenases and their inhibitors and uses. $\mathrm{J}$ Med Chem 56:3148-3167

Publisher's Note Springer Nature remains neutral with regard to jurisdictional claims in published maps and institutional affiliations. 